\title{
Tobacco smoking alters the number of oral epithelial cells with apoptotic features
}

\author{
Adam Michcik수, Miroslawa Cichorek ${ }^{2}$, Agnieszka Daca ${ }^{3}$, Piotr Chomik ${ }^{1}$, \\ Slawomir Wojcik ${ }^{4}$, Anton Zawrocki ${ }^{5}$, Adam Wlodarkiewicz ${ }^{1}$
}

\author{
${ }^{1}$ Clinic of Orofacial and Dental Surgery, Medical University of Gdansk, Poland \\ ${ }^{2}$ Department of Embryology, Medical University of Gdansk, Poland \\ ${ }^{3}$ Department of Pathophysiology, Medical University of Gdansk, Poland \\ ${ }^{4}$ Department of Anatomy and Neurobiology, Medical University of Gdansk, Poland \\ ${ }^{5}$ Department of Pathomorphology, Medical University of Gdansk, Poland
}

\begin{abstract}
Tobacco smoking is a global problem associated with the occurrence of many systemic diseases and tumors. Oral cavity tumors are common tobacco-related cancers, and of all the anatomical structures that are exposed to the effects of smoking, the oral cavity remains the least-explored area. Changes that occur in the biology of oral epithelial keratinocytes under the influence of the components of tobacco smoke often go unnoticed, if they are asymptomatic. The proper functioning of the oral epithelium is determined by the proliferation and differentiation of the cells in keratinization - the process of programmed cell death, which extends through to the mechanisms of apoptosis. Due to incomplete knowledge of the impact of tobacco smoke on the biology of keratinocytes, an evaluation of the cell cycle was conducted and the apoptosis of oral epithelial keratinocytes was analyzed. The study involved 77 patients divided into four groups according to their intensity of smoking, ranging from 0 to 27 pack-years. There were no differences in the cell count between nonsmokers and smokers in the proper cell-cycle phases. The percentage of proliferating cells in the oral epithelium is about $11 \%$. A reduction in the number of early-apoptotic cells (caspase positive/propidium iodide negative) and an increase in the number of late-apoptotic cells (caspase positive/annexin V positive/propidium iodide positive) were observed to occur with increasing pack-years. The present study demonstrates that smoking does not affect the oral keratinocyte cell cycle, but does modify the number of cells with early and late apoptotic features. An intensification of the impact of tobacco smoke components on the biology of the oral keratinocytes is clearly noticeable at approximately 6 pack-years. This indicates that the biology of the first organ exposed to tobacco smoke - the oral epithelium - is altered by tobacco smoking. (Folia Histochemica et Cytobiologica 2014, Vol. 52, No. 1, 60-68)
\end{abstract}

Key words: tobacco smoking; human oral keratinocytes; apoptosis; cell cycle; flow cytometry

\section{Introduction}

Tobacco smoking is a global problem of civilization, with the number of tobacco smokers estimated at about 1.3 billion [1]. Epidemiological studies show that one third of tobacco smokers die of cardiovascular diseases [2]. Statistically, the life expectancy of

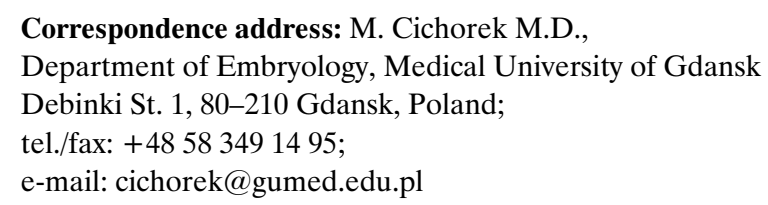

smokers is 15 years less than that of nonsmokers [3, 4]. Tobacco smoking not only increases the risk of systemic disease, but it also contributes to the risk of cancerogenesis $[5,6]$. Long-term exposure to carcinogens in the air is a high-risk factor for the development of lung cancer [1,3,4] and oral cavity cancers [7].

Tobacco smoke contains over 4000 substances that affect the human body, of which a number (about 60) are known carcinogens [8,9]. Tobacco smoke is a physically heterogeneous aerosol formed by the incomplete combustion of tobacco. During combustion, the particles are pyrolyzed (decomposed under the influence of temperature) and connect with each 
other in the process of combustion synthesis. While smoking a cigarette, the smoker absorbs about $500 \mathrm{mg}$ of smoke, of which about $65 \%$ is nitrogen and oxygen; the remaining $35 \%$ consists of biologically active substances [10].

Tobacco smoke reduces the effectiveness of the immunological system, and thus increases the risk of respiratory infections, which may also contribute to the development of malignancies [5, 11].

The effects of nicotine on epithelial cells of the respiratory tract [12-14] are well documented, but the oral cavity has not been so well explored. The results of a few studies comparing the morphology of the oral epithelium of smokers with that of nonsmokers pointed to an increase in its thickness and also to higher levels of cytokeratins in smokers' cells $[15,16]$. It is well known that epithelia exposed to adverse chemical or physical effects defend themselves by increasing cytokeratin levels [17].

The exposure of cell lines cultured in vitro in the presence of nicotine extract (the dominant substance in tobacco smoke) leads to irreversible changes that may impair fundamental processes of the cells, such as proliferation and differentiation [18-21]. Yet it is difficult to conclude the effects of tobacco smoke in vivo, where the cells are in contact with tobacco tar at a different frequency and for a long time - measured in years, and not in hours as in culture conditions. It is also extremely difficult to determine the amount of nicotine to match the levels present during smoking [22]. The assumption that cells treated in vitro with a single dose of nicotine extract will react in the same way as the cells of smokers - which are exposed to tobacco smoke many times each day, often for years - is questionable.

The outer layer of the oral mucosa is a stratified squamous epithelium that is keratinized in areas subjected to masticatory forces (e.g., the gingiva and palate). The different layers of the oral epithelium represent a progressive maturation process. Cells from the superficial keratinized layer are constantly being shed and replaced from below [23]. The homeostasis of the oral epithelium is the result of a balance between the dying and proliferating cells forming the squamous multilayered epithelium [24]. The process of keratinization is thought to be a physiological cell death, extending partly through to the mechanisms of apoptosis [25-27]. The keratinization process involves some elements from apoptotic pathways, but the final result is different. In apoptosis, cells ultimately degenerate into apoptotic bodies, while keratinocytes reach the final stage of their differentiation - during which they change size and shape and synthesize structural proteins becoming flat, filled with closely packed keratins, and surrounded by a cornified envelope of the mature cell
[23]. Progenitor cells located in the basal layer display high proliferative activity [24].

Knowledge of the effects of tobacco smoke on the percentage of epithelial cells in the oral cavity in different phases of the cell cycle is unclear, with the results of various authors differing significantly from each other [19, 28, 29].

Very little is known about the possible impact of tobacco smoke on the apoptosis of epithelial cells in the oral cavity, and observations vary, from indicating no changes on the level of apoptosis [30] to suggesting increased levels of hypodiploid cells [31] in the epithelium of smokers through the inhibition of apoptosis under influence of nicotine [20,32]. However, these observations are based on in vitro cultured keratinocytes and animal models.

The sequence of molecular events occurring during apoptosis depends on a number of factors, inducing apoptosis (inducer) and the cell's sensitivity to this type of death. There are two classic means of inducting apoptosis: through the activation of the receptors localized in the plasma membrane (the death domain receptors, such as TNFR, Fas, TRAILR) or through changes in the mitochondrial membrane $[33,34]$. The extrinsic pathway activation of the receptors leads to procaspase 8 activation, which activates the caspase 3 involved in the cell's self-destruction phase $[35,36]$. In the intrinsic (mitochondrial) pathway, apoptosis is induced by an internal factor inside a cell, such as DNA damage, increased levels of reactive oxygen species, oxidative stress, or abnormal electrolyte transport, as a result of which factors activating procaspase 9 which activates caspase 3 are released from the intermembrane space $[34,35]$. Caspase 3 induces mechanisms leading to proteolysis of important proteins (e.g., poly (ADP-ribose) polymerase and cytoskeletal proteins) and the activation of endonucleases that cut DNA into oligonucleosomal fragments $[33,37]$. Caspases are a family of cysteine proteases involved in both the initial and executive phases of apoptosis [33, 37].

The participation of caspases in the process of squamous keratinocyte differentiation is controversial [25, 26, 38-40]. Studies by Lippens et al. have shown that the activation of proapoptotic caspases is not required for the induction of epithelial keratinocyte differentiation [25]; on the other hand, Wu et al. report the participation of these proteases in the maturation of keratinocytes [26].

Proliferation, cornification, and apoptosis are fundamental processes that condition the proper functioning of the oral cavity epithelium. Due to the conflicting information about the effects of smoking on oral epithelial cells, studies of keratinocytes obtained directly from smokers could provide important data on the effects of smoke on the biology of the oral epithelium. To date, 

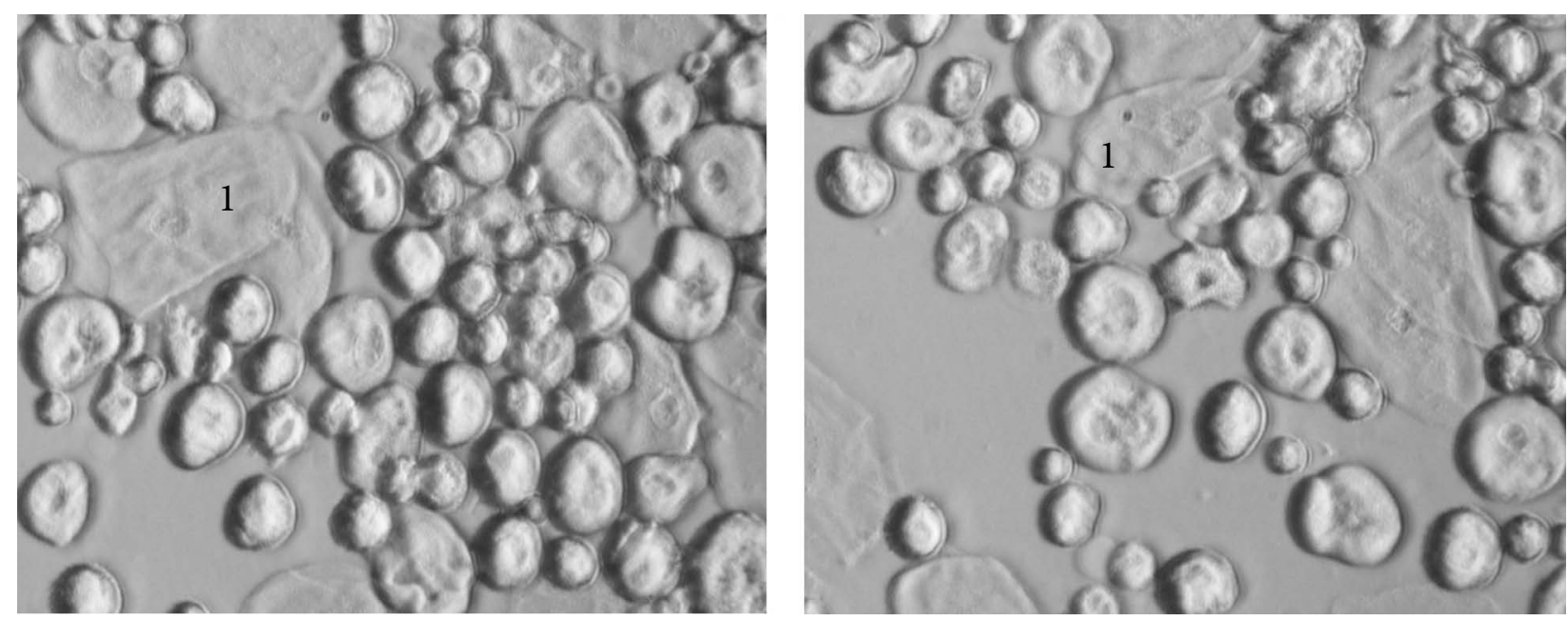

Figure 1. Morphological heterogeneity of oral epithelial cells isolated from two nonsmokers. Light microscopy with Hoffman's contrast (Nikon TS-100F microscope), number 1 denotes large flattened cells from the outer layer of the oral epithelium, total magnification $200 \times$

no markers have been set for any biological alterations produced in oral keratinocytes by tobacco smoke prior to the appearance of clinical changes. The aim of this investigation was thus to compare the cell cycle and basic parameters of apoptosis (such as caspase activation and the externalization of phosphatidylserine in the plasma membrane) of oral epithelial cells obtained from nonsmokers with those from smokers.

\section{Material and methods}

Patients. Fragments of oral mucosa were harvested during routine dental treatment (extraction of lower molars). All patients completed a detailed survey before entering the project. The form included questions on the patient's current health status, medications, smoking (the number of cigarettes smoked per day and the number of years of addiction). Patients with systemic diseases, treated chronically with drugs, and who had consumed alcohol in the past 3 days were excluded from the project. All patients were examined clinically prior to obtaining the material. Any pathology of the oral mucosa, as well as symptoms of inflammation, led patients to be excluded from the project. Thus, the cells were derived only from generally healthy patients with macroscopically intact mucosa. Patients were given sufficient information regarding the study, and all individuals signed an informed consent form. The procedures were accepted by the Ethics Committee of the Medical University of Gdansk (NKEBN/72/2011).

In the group of 77 patients, there were 40 nonsmokers (Group 1, aged $27 \pm 6.4$ years, mean \pm SD), 33 smokers (mean age $26 \pm 4.7$ years), and 4 heavy smokers with the highest average number of pack-years (mean age $51 \pm 9.5$ years). Smokers were divided into groups according to smoking intensity, expressed as pack-years. The pack-year (py) is the international unit for measuring the number of cigarettes a person has smoked over a long period, and is calculated as follows: Number of pack-years $=($ number of cigarettes smoked per day $\times$ number of years smoked)/20 (1 pack contains 20 cigarettes) [40]. The average number of pack-years for the group of 33 smokers was $3.0 \pm 2.6$. The smokers' group was therefore divided into Group 2, with pack-years equal to or less than 3.0 (20 patients with average 1.4 py) and Group 3, with more than 3.0 pack-years (13 patients with average $5.6 \mathrm{py}$ ). Groups 2 and 3 were of similar ages (mean $25 \pm 5.1$ and $27 \pm 4.2$ years, respectively), as was Group 1 of nonsmokers. A Group 4 was also distinguished, with the highest average number of pack-years of 26.9. Due to their higher average age ( 4 patients of age $51 \pm 9.5$ years), these smokers were not included in the basic analysis with Groups 2 and 3. However, in the further evaluation of the results, Group 4 was used to highlight the influence of the smoking intensity on the oral epithelium.

Isolation of cells from the oral epithelium. Fragments of the gingival oral mucosa, about $0.5 \mathrm{~cm}^{2}$ in size, were incubated in dispase $(5 \mathrm{mg} / \mathrm{mL}$, Gibco, Paisley, UK) for about 18 hours at $4^{\circ} \mathrm{C}$ to separate the epithelial sheets from the connective tissue. Single cells were obtained as the result of incubation of the oral epithelium in $0.25 \%$ trypsin-EDTA solution for $30 \mathrm{~min}$ at $37^{\circ} \mathrm{C}$ [41]. The viability of the obtained cells was over $80 \%$, as determined by trypan blue staining, and $97 \%$ of cells were keratinocytes, as determined by staining cells with a mixture of antibodies against cytokeratins (anti human cytokeratin clone AE1/AE3, Dako, Glostrup, Denmark). The obtained keratinocytes originated from all layers of the oral epithelium, as was documented by microscopic analysis of the cells' morphological heterogeneity (Figure 1). 
Cell cycle analysis. $1 \times 10^{6}$ ethanol-fixed keratinocytes were resuspended in $1 \mathrm{ml}$ of staining solution (RNase A $200 \mu \mathrm{g} / \mathrm{mL}$ and propidium iodide (PI) $5 \mu \mathrm{g} / \mathrm{mL}$ in PBS). Then cells were incubated for $30 \mathrm{~min}$ at $37^{\circ} \mathrm{C}$ in the dark. 20,000 cells were analyzed on a FACS Calibur flow cytometer (Becton Dickinson Immunocytometry System, San Jose, CA, USA). The results were analyzed off-line using Cyflogic software (CyFlo Ltd).

Cytofluorimetric estimation of number of cells with activated caspases. We applied the FLICA test (fluorochrome-labeled inhibitors of caspases) to estimate the number of cells with activated caspases [42]. The idea behind this method is based on the fact that fluorochrome-labeled inhibitors of caspases react covalently with the reactive enzymatic centers of the activated caspases. We used FITC-(fluorescein)-labeled pan-caspase inhibitor VAD-FMK (VAD, three amino acids peptide; FMK, fluoro-methyl ketone, which binds to cysteine of caspase), which detects all activated caspases in the cell, as the three-amino-acid target sequence binds to most caspases. In this method, simultaneous staining of cells with FITC-VAD-FMK and PI allows to distinguish the sequential stages of apoptosis which were described as: (i) early apoptosis: here the cells have a high intensity of green fluorescence, which indicates a high level of activated caspases $(\mathrm{C}+)$, but exclude $\mathrm{PI}$, as the plasma membrane is not damaged (PI-); they were denoted $\mathrm{C}+/ \mathrm{PI}-$ (caspase positive/ PI negative); (ii) late apoptosis: here the cells bind FITC-VAD-FMK to the activated caspases $(\mathrm{C}+)$ and are stained by PI, because the plasma membrane is damaged (PI+); denoted as $\mathrm{C}+/ \mathrm{PI}+$ (caspase positive/PI positive); (iii) final stage of apoptosis: here the cells are stained by PI (PI+), but do not have active caspases (C-); denoted C-/PI+ (caspase negative/PI positive).

From each patient, $0.5 \times 10^{6}$ cells were incubated with $5 \mu \mathrm{M}$ FITC-VAD-FMK (CaspACE ${ }^{\mathrm{TM}}$ FITC-VAD-FMK, Promega, Madison, USA) for $30 \mathrm{~min}$ at room temperature in the dark, before being washed and resuspended in PBS (phosphate-buffered saline) containing PI. 20,000 cells were analyzed on a flow cytometer.

Changes in the plasma membrane structure: externalization of phosphatidylserine. Externalization of phosphatidylserine (PS) is commonly used as a marker of apoptotic change in plasma membranes, which is a signal for macrophages to phagocytise the cell. The annexin V-binding test was used to estimate PS exposure on the plasma membrane surface (Annexin V-Fluos staining kit, Roche, Mannheim, Germany). Simultaneous staining with annexin V-FITC (detecting both apoptotic and necrotic cells with phosphatidylserine residues exposed on their surface) and PI (staining DNA in the cells with damaged plasma membrane, e.g., dead cells) allows discrimination between early and late apoptotic cells. Thus, the Annexin V test characterizes the sequential stages of apoptosis like the FLICA test: (i) early apoptotic cells bind annexin V but do not stain with PI (annexin positive/ PI negative, An+/PI-); (ii) late apoptotic/necrotic cells bind annexin $\mathrm{V}$ and stain with PI (annexin positive/PI positive, An+/PI+). Cells were stained with Annexin V-FITC and PI according to manufacturer's instructions and analyzed on a flow cytometer.

Microscopic analyses. Initial microscopic analysis of the oral epithelial cells in a bright field with Hoffman's contrast was performed on a TS-100F light microscope (Nikon, Tokyo, Japan). The colocalization study of stained epithelial cells (FLICA, annexin V and PI) was performed using a Radiance 2100 confocal laser-scanning microscopy (CMLS) system (Bio-Rad, Hemel Hempstead, UK) mounted on Nikon Eclipse 600 microscope. The CMLS images were obtained with $40 \times$ and $60 \times$ oil-immersion objective lenses with N.A. of 1.3 and 1.4, respectively. The optimal iris diameter was used for each magnification. The CMLS images were analyzed using LaserSharp 2000 and LaserPix v. 2.0 software (Bio-Rad).

Statistical analysis. The group data are expressed as arithmetic means \pm SD. Statistical analysis was performed using the ANOVA Kruskal-Wallis test and the Dunn test. Differences at $\mathrm{p}<0.05$ were considered significant. The tests were performed using Statistica data analysis software system, version 10 (StatSoft, Inc., 2011, www. statsoft.com).

\section{Results}

\section{Analysis of cell cycle of oral epithelial cells}

The analysis of the cell cycle (Table 1) in the oral epithelium of nonsmokers (Group 1) showed that the percentage of cells in the individual phases was $82.1 \%$ for $\mathrm{G} 0 / \mathrm{G} 1,7.1 \%$ for $\mathrm{S}$, and $4.3 \%$ for $\mathrm{G} 2 / \mathrm{M}$. For the Group 3 (smokers with 5.6 py), these values were $78.7 \%, 8.5 \%$, and $3.4 \%$, respectively. Thus, smoking about 6 pack-years did not significantly change the number of cells in the various cell cycle phases. There was, however, a tendency for the percentage of cells in the $S$ phase to increase with pack- years of smoking (Table 1).

\section{Morphologic assessment of apoptosis of oral keratinocytes with confocal microscopy}

The FLICA-stained oral keratinocytes indicated that caspases were localized in the cytoplasm and that their activity was heterogeneous (Figure 2A). Caspases -positive cells occurred among cells of all sizes, and the largest cells from the outer epithelial layers also contained activated caspases (Figure 2B). 
Table 1. Cell cycle analysis of the oral epithelial cells from subjects with different smoking intensity (expressed as pack-years, py)

\begin{tabular}{|l|c|c|c|}
\hline Percentage of cells in the cell cycle phase & Group 1 (Control, 0 py) & Group 2 (1.4 $\pm \mathbf{1}$ py) & Group 3 (5.6 $\pm \mathbf{2 . 1}$ py) \\
\hline G0/G1 & $82.1 \pm 5.0$ & $83.0 \pm 4.0$ & $78.7 \pm 7.0$ \\
\hline S & $7.1 \pm 2.2$ & $7.6 \pm 2.1$ & $8.5 \pm 2.9$ \\
\hline G2/M & $4.3 \pm 1.7$ & $3.8 \pm 1.0$ & $3.4 \pm 1.5$ \\
\hline
\end{tabular}

Values are means $\pm \mathrm{SD}$
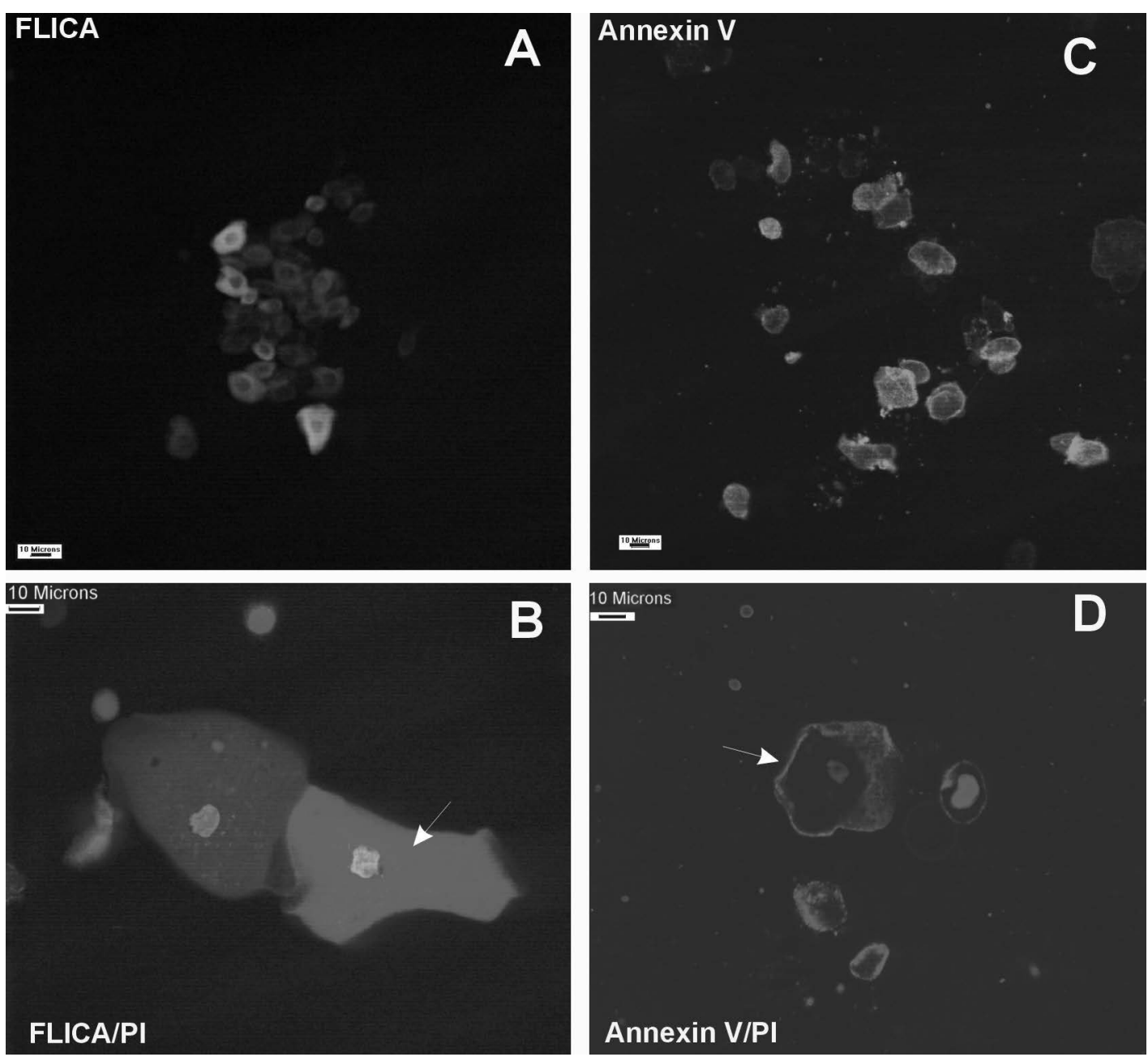

Figure 2. Activated caspases and phosphatidylserine externalization in oral epithelial cells isolated from one nonsmoker studied by confocal laser-scanning microscopy. FLICA test (A, B) and Annexin V test (C, D) staining are shown. A. Activated caspases present in cells of all sizes; $\mathbf{B}$. The arrow indicates cytoplasm with high FITC-VAD-FMK fluorescence; C. Phosphatidylserine externalization present in cells of all sizes; D. The arrow shows Annexin V-FITC fluorescence in the plasma membrane. Scale bar $10 \mu \mathrm{m}$

Annexin V-FITC staining showed that externalization of PS also affected cells of all sizes, (Figure 2C) among which are flattened cells with degenerating nuclei from the outer epithelial layers (Figure 2D).

\section{Analysis of cells with apoptotic death features}

\section{Activated caspases}

The overall number of cells with activated caspases was similar in all examined groups, but the detailed 
Table 2. Percentage of the oral epithelial cells with apoptotic features in subjects with different smoking intensity (expressed as pack-years, py)

\begin{tabular}{|l|c|c|c|c|}
\hline \multirow{2}{*}{ Apoptotic features } & $\begin{array}{c}\text { Group 1 } \\
\text { (Control, 0 py) }\end{array}$ & $\begin{array}{c}\text { Group 2 } \\
(\mathbf{1 . 4} \pm \mathbf{1} \text { py })\end{array}$ & $\begin{array}{c}\text { Group 3 } \\
(\mathbf{5 . 6} \pm \mathbf{2 . 1} \text { py) }\end{array}$ & $\begin{array}{c}\text { Group 4 } \\
(\mathbf{2 6 . 9} \pm \mathbf{1 5 . 7} \text { py) }\end{array}$ \\
\cline { 2 - 5 } & \multicolumn{3}{|c|}{ Percentage of cells with apoptotic features (\%) } \\
\hline 1. Activated caspases & & & & \\
Early apoptotic C+/PI- & $20.1 \pm 6.2$ & $16.6 \pm 7.5$ & $14.5 \pm 5.2^{\mathrm{a}}$ & $13.2 \pm 4.6$ \\
Late apoptotic C+/PI+ & $9.2 \pm 4.6$ & $9.6 \pm 4.0$ & $10.6 \pm 4.2$ & $16.9 \pm 5.9^{\mathrm{a}}$ \\
Cells at the final apoptosis C-/PI+ & $0.7 \pm 0.8$ & $1.7 \pm 2.4$ & $2.2 \pm 2.3^{\mathrm{b}}$ & $1.0 \pm 0.4$ \\
\hline 2. Phosphatidylserine externalization: & & & & $9.5 \pm 2.5$ \\
Early apoptotic An+/PI- & $9.5 \pm 5.2$ & $10.0 \pm 5.6$ & $9.3 \pm 3.1$ & $32.5 \pm 7.7^{\mathrm{a}}$ \\
Late apoptotic An+/PI+ & $19.3 \pm 7.3$ & $21.8 \pm 8.1$ & $23.6 \pm 7.9$ & \\
\hline 3. Hypodiploid DNA content & & & & $7.5 \pm 7.1$ \\
(cells in the sub G0 region) & $3.0 \pm 2.5$ & $2.4 \pm 1.2$ & $5.6 \pm 4.9$ & 7.9 \\
\hline
\end{tabular}

Classification of cells into the early, late and final apoptotic stages was based on criteria described in Materials and Methods. Values are means \pm SD. ${ }^{a}$ and ${ }^{b}$ significantly different from the corresponding values of the control group (nonsmokers), $p<0.05$ and $p<0.01$, respectively (Kruskal-Wallis test)

analysis of the apoptotic stages showed significant differences between nonsmokers and smokers (Table 2). Analysis of the oral keratinocytes of nonsmokers revealed that about $30 \%$ of all cells had activated caspases; in this group early apoptotic cells with intact plasma membrane (C+/PI-) dominated (Table 2). Smoking habit decreased the population of early apoptotic cells to $14.5 \%$ for Group 3 (5.6 py) with a reduction of $28 \%$ in comparison to nonsmokers (Table 2). Interestingly, the number of late apoptotic cells with damaged plasma membranes $(\mathrm{C}+/ \mathrm{PI}+)$ in the Group 4 (26.9 py) was significantly higher than in nonsmokers (Table 2, Figure 3). About $1 \%$ of oral keratinocytes of nonsmokers stained with PI, but lacked activated caspases (C-/PI+). This population increased for Group 3 to $2 \%$ (Table 2).

\section{Plasma membrane changes: phosphatidylserine externalization}

In the group of nonsmokers, about $29 \%$ of cells showed PS externalization, while those smoking 26.9 pack years had a significant increase, possessing over $40 \%$ of such cells. This change was mainly related to late apoptotic cells with damaged plasma membranes $($ An+/PI+, Table 2, Figure 3).

Summarizing the observed changes in caspase activation and plasma membrane, it was noted that, with increased pack-years of smoking, the number of cells with late apoptotic features (high activity of caspases, PS externalization, damaged cell membrane) increases, as illustrated in Figure 4.

\section{Effect of smoking on the content of cells with reduced DNA content}

The percentage of dying cells with reduced DNA levels (e.g., apoptotic bodies) located in the SubG0 part of the cell cycle increased with pack-years of smoking (Table 2). Among nonsmokers, these constituted 3\% of the cells, while for the Group 3 smokers, the population of such cells almost doubled. In people smoking 26.9 pack-years the level of cells with reduced DNA amount was about $7 \%$ (Table 2).

\section{Discussion}

In the present study, we have demonstrated that tobacco smoking induced changes in the apoptosis of human oral keratinocytes, which may be signs of alterations in oral epithelium biology.

The limited information available in the literature concerning the proliferation potential of oral keratinocytes indicates that nicotine can increase or decrease the number of proliferating cells in vitro [19, 31]. Our results, based on cells obtained directly from smokers, showed no significant difference with cells from nonsmokers. Among nonsmokers, only $11 \%$ of the cells were in the S/G2/M phases - much lower than predicted by other authors who had examined oral keratinocytes $[19,28,29]$ and epidermal keratinocytes $[19,43]$. This higher percentage of cells in the $\mathrm{S} / \mathrm{G} 2 / \mathrm{M}$ phases is probably due to the fact that most of these observations were carried out on cultured cell lines, and not on cells obtained directly from patients. 


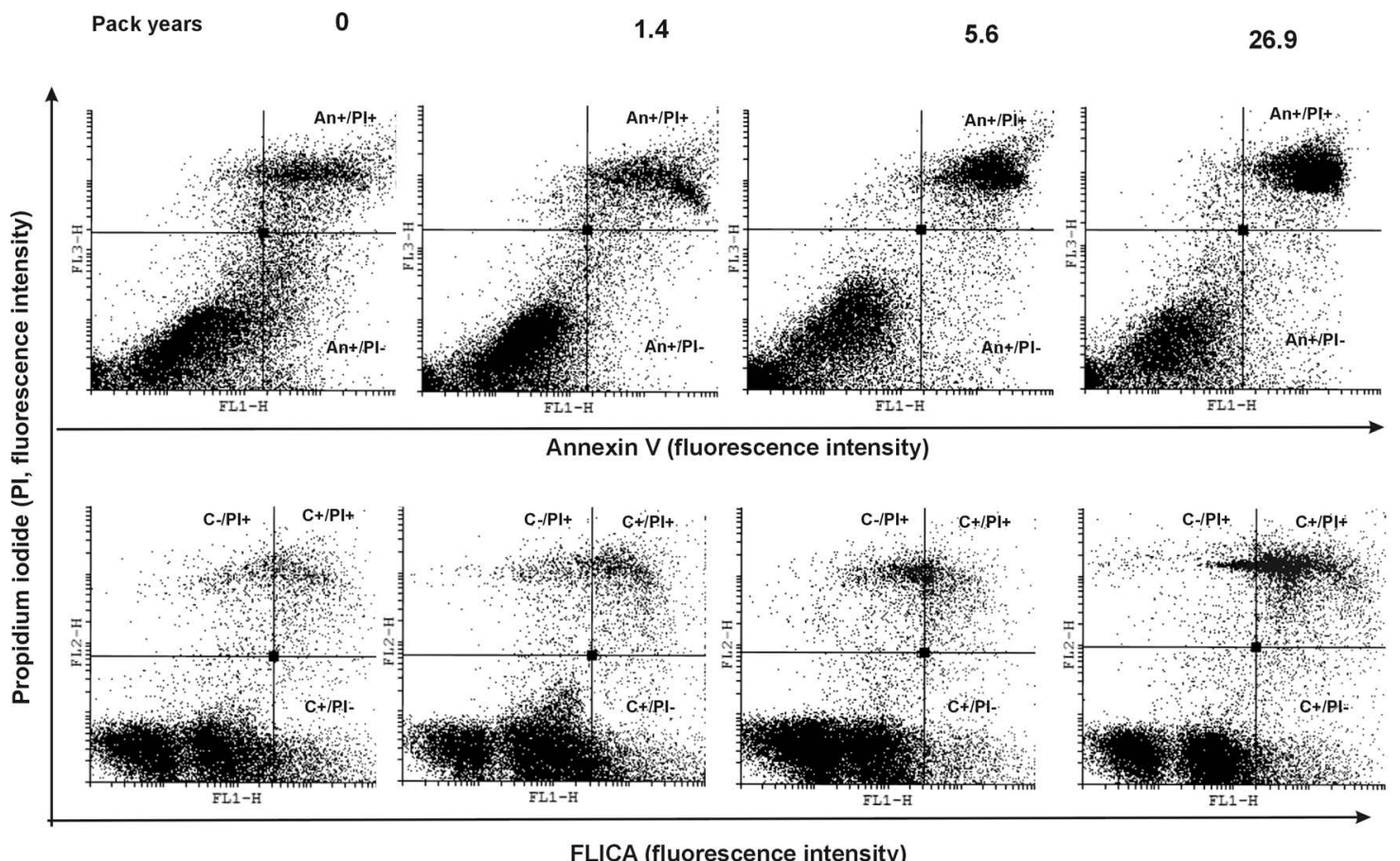

Figure 3. Flow cytometric analysis of oral epithelial cells with active caspases (FLICA test) and externalized phosphatidylserine (Annexin V test) from examined groups of subjects with different smoking intensity expressed as pack-years (py). Density plots of a representative subject from each group. The plot is divided into identical quadrants containing: lower right: $\mathrm{C}+/ \mathrm{PI}-$, $\mathrm{An}+/ \mathrm{PI}-$, early apoptotic cells; upper right $\mathrm{C}+/ \mathrm{PI}+, \mathrm{An}+/ \mathrm{PI}+$, late apoptotic cells; upper left $\mathrm{C}-/ \mathrm{PI}+$, cells in the final stage of apoptosis (C, caspases; An, annexin; PI, propidium iodide)
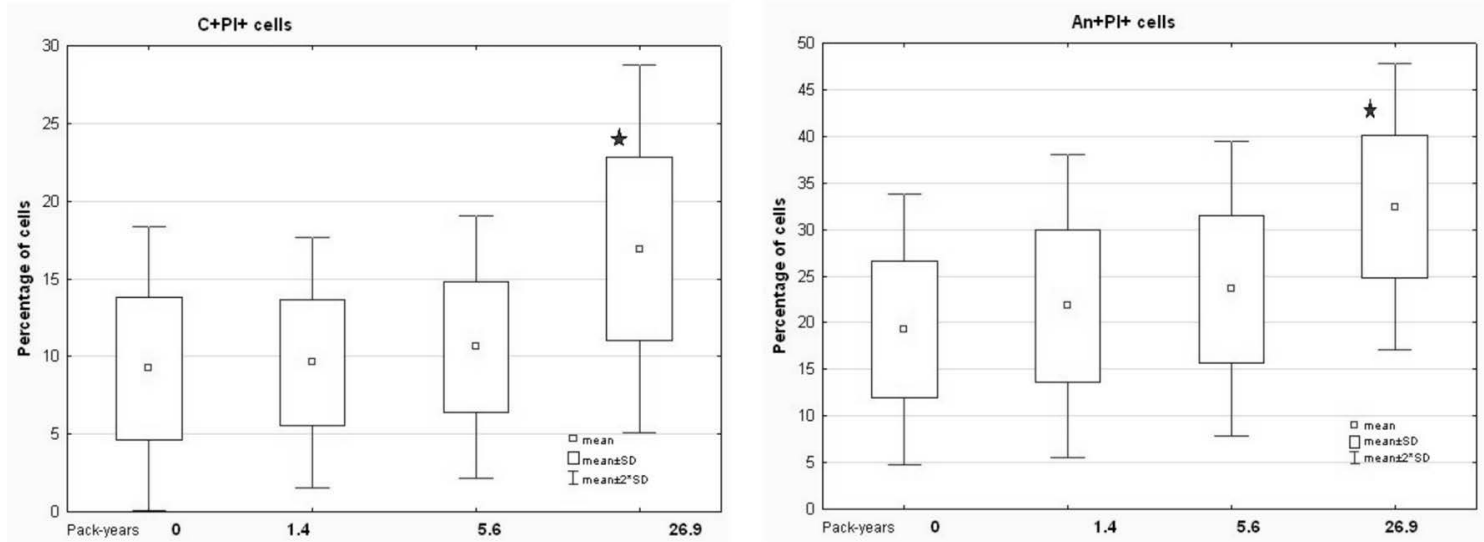

Figure 4. Percentage of late apoptotic cells with activated caspases $(\mathrm{C}+)$, phosphatidylserine externalization $($ An +$)$, and discontinuous plasma membrane (PI+) in examined groups with different smoking intensity expressed as pack-years. *significantly different from control, $\mathrm{p}<0.05$ (Dunn test)

Our finding that there was no significant difference between nonsmokers and smokers with 6 pack-years of smoking in the percentages of cells in individual cell cycle phases are difficult to discuss, because there are no similar flow cytometric analyses in the available literature based on material obtained directly from smokers. It is worth noticing that the smokers exami- ned in our study showed no macroscopic changes in the oral cavity that might be the result of disturbances in epithelial cell proliferation.

Keratinization is thought to be a process of physiological cells death which occurs as the result of the process of cell differentiation [26, 27]. The majority of publications which evaluated the influence of to- 
bacco smoke on the intracellular processes of oral keratinocytes, examined only the general features of apoptosis - such as caspase activation, and changes in mitochondria, plasma membrane, and chromatin. The participation of caspases in the process of differentiation of squamous keratinocytes is controversial [25, 26, 38, 39]. The studies of Lippens et al. have shown that the activation of proapoptotic caspases is not required for the induction of differentiation of epithelial keratinocytes [25], while Wu et al. have reported on the participation of these proteases in the maturation of keratinocytes [26]. Our results clearly document that this group of enzymes is presented in the oral keratinocytes of all epithelial layer cells, but that the amount of activated caspase differs. These observations need further studies to estimate the types of caspase that appear in oral keratinocytes, as there is uncertain information about this in the literature [25, 26]. For a complete understanding of changes occurring during apoptosis, an analysis that distinguishes the stages of the ongoing physiological apoptotic death would allow the dynamics of this process to be followed. We have found that, for 6 pack-year smokers, the population of cells with activated caspases and undamaged plasma membranes decreases, but that with prolonged smoking at 27 pack-years, the number of cells with activated caspases, phosphatidylserine externalization, and lost integrity in the plasma membrane significantly increases. To our knowledge, ours is the first study to provide evidence that smoking alters the number of cells with apoptotic features, using oral keratinocytes obtained directly from smokers. The observed increased level of late apoptotic cells is similar to the results of other reports, in which tobacco smoke extract increased the level of annexin $\mathrm{V}$ positive/PI positive or 7-AAD positive cells among oral epithelial cell lines cultured in vitro $[28,44]$. Additionally, increased levels of late-apoptotic cells (annexin $\mathrm{V}$ positive/ /PI positive) were observed by Zhang et al. who evaluated the impact of cigarette smoke extract on the bronchial epithelial cell line HBE1 [45]. Unlike our study and the above-cited studies, there are reports that showed that cotinine and nicotine inhibited apoptosis of cells other than keratinocytes, and in particular of tumor cells - which is supposed to be a factor promoting tumor growth [46, 47].

The altered number of oral epithelial cells with early and late apoptotic features with increased time of smoking indicates interference with the physiological death of oral keratinocytes - a basic process in oral epithelium homeostasis. It is worth to note that despite changes at the microscopic level prolonged smoking did not result in macroscopic alterations of the oral mucosa. However, ultrastructural studies of the oral mucosa cytoarchitecture of heavy smokers revealed reductions in desmoglein 3 and keratin 10 expressions [30].

In summary, the present study demonstrates that smoking at the rate of 6 pack-years did not affect cell cycle of human oral keratinocytes, but altered the number of cells with apoptotic features with increasing pack-years of smoking. Our study is the first observation in humans, however, the investigations on a group of smokers with longer-lasting habit could provide more data about the interference of smoking with the biology of oral keratinocytes.

\section{Acknowledgment}

We thank Professor Jacek M. Witkowski for help in the analysis of flow cytometric measurements on a FACS Calibur flow cytometer in the Department of Pathophysiology, Medical University of Gdansk, Poland

\section{References}

1. Thun M. Peto R. Boreham J. Lopez AD. Stages of the cigarette epidemic on entering its second century. Tob Control. 2012;21:96-101.

2. Teo KK. Ounpuu S. Hawken S et al. Tobacco use and risk of myocardial infarction in 52 countries in the INTERHEART study: a case-control study. Lancet. 2006;368:647-658.

3. Didkowska J, Manczuk M, McNeill A, Powles J, Zatonski W. Lung cancer mortality at ages 35-54 in the European Union: ecological study of evolving tobacco epidemics. $B M J$. 2005;331:189-191.

4. Jemal A, Siegel R, Ward E, Hao Y, Xu J. Thun M. Cancer statistics 2009. CA Cancer J Clin. 2009; 59:225-249.

5. Wogan GN, Hecht SS, Felton JS, Conney AH, Loeb LA. Environmental and chemical carcinogenesis. Semin Cancer Biol. 2004;14:473-486.

6. Gagat M, Grzanka D, Izdebska M, Maczynska E, Grzanka A. Nornicotine impairs endothelial cell-cell adherens junction complexes in the EA.hy926 cell line via structural reorganization of F-actin. Folia Histochem Cytobiol. 2013;51:179-192.

7. Agudo A, Bonet $\mathrm{C}$, Travier $\mathrm{N}$ et al. Impact of cigarette smoking on cancer risk in the European prospective investigation into cancer and nutrition study. J Clin Oncol. 2012;30:4550-4557.

8. Munteanu I, Didilescu C. Chemistry and toxicology of cigarette smoke in the lungs. Pneumologia. 2007;56:43-46.

9. Pappas RS. Toxic elements in tobacco and in cigarette smoke: inflammation and sensitization Metallomics. 2011;3: 1181-1198.

10. Liu X, Conner H, Kobayashi T. Cigarette smoke extract induces DNA damage but not apoptosis in Human Bronchial Epithelial Cells. Am J Respir Cell Mol Biol. 2005;33:121-129.

11. Hoser G, Kawiak J, Domagała-Kulawik J, Kopiński P, Droszcz W. Flow cytometric evaluation of lymphocyte subpopulations in BALF of healthy smokers and nonsmokers. Folia Histochem Cytobiol. 1999;37:25-30.

12. Sridhar S, Schembril F, Zeskind J et al. Smoking-induced gene expression changes in the bronchial airway are reflected in nasal and buccal epithelium. BMC Genomics. 2008;9:259. doi:10.1186/1471-2164-9-259. 
13. Pickett G, Seagrave J, Boggs S, Polzin G, Richter P, Tesfaigzi Y. Effects of 10 cigarette smoke condensates on primary human airway epithelial cells by comparative gene and cytokine expression studies. Toxicol Sci. 2010;114:79-89.

14. Shaykhiev R, Otaki F, Bonsu P et al. Cigarette smoking reprograms apical junctional complex molecular architecture in the human airway epithelium in vivo. Cell Mol Life Sci. 2011;68:877-892.

15. Villar CC, de Lima AF. Smoking influence on the thickness of marginal gingival epithelium. Pesqui Odontol Bras. 2003;17:41-45.

16. Gultekin SE, Senguven B, Karaduman B. The effect of smoking on epithelial proliferation in healthy and periodontally diseased marginal gingival epithelium. $J$ Periodontol. 2008;79:1444-1450.

17. Presland RB, Dale BA. Epithelial structural proteins of the skin and oral cavity: Function in health and disease. Crit Rev Oral Biol Med. 2000;11:383-408.

18. Grando SA, Horton RM, Mauro TM, Kist DA, Lee TX, Dahl MV. Activation of keratinocyte nicotinic cholinergic receptors stimulates calcium influx and enhances cell differentiation. $J$ Invest Dermatol. 1996;107:412-418.

19. Lee HJ, Guo HY, Lee SK et al. Effects of nicotine on proliferation, cell cycle, and differentiation in immortalized and malignant oral keratinocytes.J Oral Pathol Med. 2005;34:436-443.

20. Banerjee AG, Gopalakrishan VK, Vishvanatha JK. Inhibition of nitric oxide-induced apoptosis by nicotine in oral epithelial cells. Mol Cell Biochem. 2007; 305:113-121.

21. Reno F, Rocchetti V, Migliario M, Rizzi M, Cannas M. Chronic exposure to cigarette smoke increases matrix metalloproteinases and filaggrin mRNA expression in oral keratinocytes: Role of nicotine stimulation. Oral Oncol. 2011;47:827-830.

22. Zeidler R, Albermann K, Lang S. Nicotine and apoptosis. Apoptosis. 2007;12:1927-1943.

23. Squier C, Fikelstein M, Oral mucosa. In: Nanci A. (ed.). Ten Cate's oral histology: development, structure, and function. $6^{\text {th }}$ ed., Missouri, Mosby Inc. 2003:329-374.

24. Lehrer MS, Sun TT, Lavker RM. Strategies of epithelial repair: modulation of stem cell transit amplifying cell proliferation. J Cell Sci. 1998;111:2867-2875.

25. Lippens S, Denecker G, Ovaere P, Vandenabeele P, Declerq W. Death penalty for keratinocytes: apoptosis versus cornification. Cell Death Differ. 2005;12:1497-1508.

26. Wu NL, Lee TA, Tsai TL, Lin WW. TRAIL-induced keratinocyte differentiation requires caspase activation and p63 expression. J Invest Dermatol. 2011;131:874-883.

27. Zhou Y, Cheng Y, Feng D, Ling B, Liu P. Induction the cornification of squamous cancerous cells to eliminate tumor cells by promotion cell differentiation and stratum. Med Hypotheses. 2011;77:763-764.

28. Jiao ZX, Ao QL, Xiong M. Cigarette smoke extract inhibits the proliferation of alveolar epithelial cells and induces apoptosis. Acta Physiologica Sinica. 2006;3:244-254.

29. Ohnuki $\mathrm{H}$, Izumi $\mathrm{K}$, Terada $\mathrm{M}$ et al. Zoledronic acid induces S-phase arrest via a DNA damage response in normal human oral keratinocytes. Arch Oral Biol. 2012;57:906-917.
30. Donetti E, Gualerzi A, Bedoni M et al. Desmoglein 3 and keratin 10 expressions are reduced by chronic exposure to cigarette smoke in human keratinized oral mucosa explants. Arch Oral Biol. 2010;10:815-823.

31. Schwartz J, Muscat J, Baker V et al. Oral cytology assessment by flow cytometry of DNA adducts, aneuploidy, proliferation and apoptosis shows differences between smokers and non-smokers. Oral Oncol. 2003;39:842-854.

32. Assis GF, Ceolin DS, Marques ME, Salvadori DM, Ribeiro DA. Cigarette smoke affects apoptosis in rat tongue mucosa: role of Bcl-2 gene family. J Mol Hist. 2005;36:483-489.

33. Zhivotovsky B. Caspases: the enzymes of death. Essays Biochem. 2003;39:25-40.

34. Orrenius S. Mitochondrial regulation of apoptotic cell death. Toxicol Lett. 2004;49:19-23.

35. Loro L, Vintermyr OK, Johannessen AC. Apoptosis in normal and diseased oral tissues. Oral Diseases. 2005;11:274-287.

36. Ho PK, Hawkins CJ. Mammalian initiator apoptotic caspases. FEBS J. 2005;272:5436-5453.

37. Fischer U, Janicke RU, Schulye-Osthoff K. Many cuts to ruin: a comprehensive update of caspase. Cell Death Differ. 2003;10:76-100.

38. Lamkanfi M, Festjens N, Declercq W, Vanden Berghe T, Vandenabeele P. Caspases in cell survival, proliferation and differentiation. Cell Death Differ. 2007;14:44-55.

39. Nhan TQ, Liles WC, Schwartz SM. Physiological functions of caspases beyond cell death. Am J Pathol. 2006;169:729-737.

40. Janjigian YY, McDonell K, Kris M et al. Pack years of cigarette smoking as a prognostic factor in patients with Stage IIIB/ IV Non-Small Cell Lung Cancer. Cancer. 2010;116:670-675.

41. Drukała J, Zarzecka J, Gojniczek K, Waligórska A, Zapała J, Korohoda W. Comparison of proliferation and motile activity between human keratinocytes isolated from skin and oral mucosa. Folia Biol. 2005;53:21-28.

42. Smolewski P, Grabarek J, Halicka H, Darzynkiewicz Z. Assay of caspase activation in situ combined with probing plasma membrane integrity to detect three distinct stages of apoptosis. J Immunol Methods. 2002;265:111-117.

43. Lai WW, Hsiao YP, Chung JG, Wei YH, Cheng YW, Yang YH. Synergistic phototoxic effects of glycolic acid in a human keratinocyte cell line (HaCaT). J Dermatol Sci. 2011;64:191-198.

44. Gao H, Prasad GL, Zacharias W. Differential cell-specific cytotoxic responses of oral cavity cells to tobacco preparations. Tox In Vitro. 2012;27:282-291.

45. Zhang H, Shih A, Rinna A, Forman HJ. Exacerbation of tobacco smoke mediated apoptosis by resveratrol: An unexpected consequence of its antioxidant action. Int J Biochem Cell Biol. 2011;43:1059-1064.

46. Dasgupta P, Kinkade R, Joshi B, Decook C, Haura E, Chellappan S. Nicotine inhibits apoptosis induced by chemotherapeutic drugs by up-regulating XIAP and survivin. Proc Natl Acad Sci USA. 2006;103:6332-6337.

47. Nakada T, Kiyotani K, Iwano S et al. Lung tumorigenesis promoted by anti-apoptotic effects of cotinine, a nicotine metabolite through activation of PI3K/Akt pathway.J Toxicol Sci. 2012;37:555-563. 